\title{
Effects of clinical and laboratory variables at admission and of in-hospital treatment with cardiovascular drugs on short term prognosis of ischemic stroke. The GIFA study
}

\author{
A. Tuttolomondo a,*, D. Di Raimondo a, R. Di Sciacca ${ }^{\text {a }}$, \\ C. Pedone ${ }^{b}$, S. La Placa ${ }^{a}$, V. Arnao ${ }^{c}$, A. Pinto ${ }^{a}$, G. Licata ${ }^{a}$

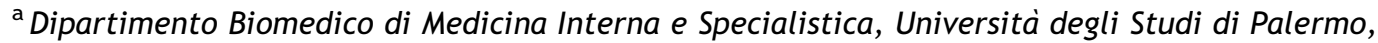 \\ P.zza delle Cliniche, n.2, 90127 Palermo, Italy \\ ${ }^{\mathrm{b}}$ Cattedra di Geriatria e Gerontologia, Campus Biomedico Roma, Italy \\ 'Dipartimento di Biomedicina Sperimentale e Neuroscienze Cliniche, Università degli Studi di \\ Palermo, Italy
}

Received 30 August 2011; received in revised form 19 January 2012; accepted 25 January 2012 Available online 12 April 2012

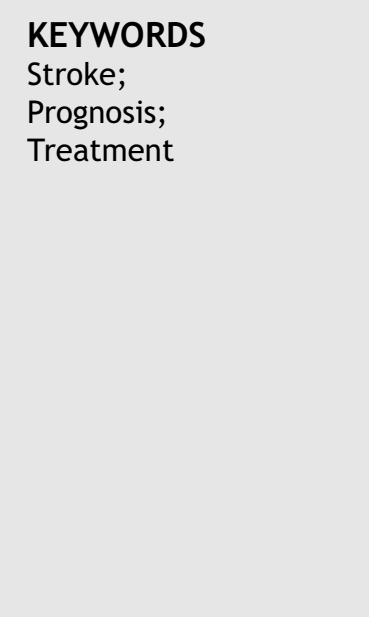

\begin{abstract}
Introduction: No information exists, to our knowledge, about the possible role of cardiovascular drug administration in the acute phase of ischemic stroke and possible effects on stroke outcome. The aim of our study was to evaluate the relationship between in-hospital treatment with cardiovascular drugs in patients with acute ischemic stroke and some outcome indicators. Methods and Results: 1096 subjects enrolled in the GIFA study, who had a main discharge diagnosis of ischemic stroke represent the final sample. Drugs considered for the analysis were the following: ACE-inhibitors (ACEI), angiotensin II receptor blockers (ARBs), statins, calciumchannel-blockers (CCBs), antiplatelet (APL) drugs, antivitamin-k (VKAs), and heparins. As outcome indicators we choose in-hospital mortality, cognitive function evaluated by Hodkinson Abbreviated Mental Test (HAMT), and functional status evaluated by activity daily living (ADL). Indicators of a good outcome were: no in-hospital mortality, HAMT $>6$ and 0 ADL impaired. Patients with a good outcome showed a higher rate of in-hospital treatment with ACEinhibitors, calcium-channel blockers and a lower rate of pre-treatment with heparin.

Conclusions: Our study suggests that if a patient with acute ischemic stroke has higher SBP at admission, higher total cholesterol plasma levels, a lower Charlson index and is treated with ACE-inhibitors, calcium channel blockers and antiplatelet drugs, the short term outcome is better
\end{abstract}

* Corresponding author. Tel.: +39091 6552128; fax: +390916552285.

E-mail address: brunotutto@unipa.it (A. Tuttolomondo). 
in terms of in-hospital mortality and functional indicators such as cognitive and functional performance at discharge.

(c) 2012 Elsevier B.V. All rights reserved.

\section{Introduction}

Pre-treatment with several active cardiovascular drugs such as statins [1], antiplatelets [2] and ACE-inhibitors [3] are associated with a better outcome in subjects with acute ischemic stroke.

All these studies evaluated effects of these active cardiovascular drugs on NIHSS scores, but no study evaluated, to our knowledge, possible effects of in-hospital treatment with these drugs on in-hospital mortality or other outcome indicators such as indexes of functional and cognitive outcome.

Recently our group evaluated the relationship between a favourable outcome and cardiovascular drug pretreatment prior of hospital admission [4]

On this basis our aim was to evaluate the relationship between in-hospital treatment with cardiovascular drugs such as ACE-inhibitors (ACEI), angiotensin II receptor blockers (ARBs), calcium channel blockers (CCBs), antiplatelet drugs (APL), anti-vitamin K (VKAs) drugs and heparin and a favourable outcome in subjects with acute ischemic stroke.

\section{Methods}

\section{Patients and setting}

The study protocol of the Italian Group of Pharmacoepidemiology in the Elderly (Gruppo Italiano di Farmacoepidemiologia nell'Anziano [GIFA]) study has been described elsewhere [5].

Briefly, the GIFA is a multicenter periodical survey of hospitalized older patients. All patients admitted to 81 clinical centers homogeneously distributed throughout Italy were enrolled and followed-up until discharge. For this project, only patients enrolled during 1993, 1995, 1997, and 1998 surveys were considered. Data collected in 1988 and 1991 were not included because most of the randomized clinical trials showing the protective effect of antithrombotic therapy were published in the 1990 s.

\section{Prevalent disease findings}

All diseases diagnosed by the physicians were classified according to the International Classification of Disease, 9th revision (ICD-9). Cases of ischemic stroke were identified on the basis of the ICD-9 code (434-434.9, 436, 433.01, and 435 to 435.9 , respectively).

To estimate the global burden of diseases, an index of co-morbidity was calculated using the Charlson index $(\mathrm{Cl})$ score, modified by Deyo et al. [6]. Subjects were classified into 2 co-morbidity groups as follows: Charlson index $<2$ and Charlson index $>2$. The Charlson co-morbidity index predicts the ten-year mortality for a patient who may have a range of co-morbid conditions such as heart disease, AIDS, or cancer (a total of 22 conditions). Each condition is assigned with a score of 1,2,3 or 6 depending on the risk of dying associated with this condition. Then the scores are summed up and given a total score which predicts mortality.

The clinical conditions and scores are as follow: 1 each: Myocardial infarct, congestive heart failure, peripheral vascular disease, dementia, cerebrovascular disease, chronic lung disease, connective tissue disease, ulcer, chronic liver disease. 2 each: Hemiplegia, moderate or severe kidney disease, diabetes, diabetes with complication, tumor, leukemia, lymphoma. 3 each: Moderate or severe liver disease. 6 each: Malignant tumor, metastasis, AIDS.

To estimate the burden of arterial blood pressure values at admission on stroke prognosis, enrolled subjects were classified into three different groups in relation of systolic blood pressure (SBP) values at admission: 1) SBP $\geq 120$ and $\leq 180 \mathrm{~mm} / \mathrm{Hg}$; 2) SBP $<120 \mathrm{~mm} / \mathrm{Hg}$; SBP $>180 \mathrm{mmHg}$.

\section{Ascertainment of drug prescription}

All new prescribed drugs during hospital stay were abstracted from hospital charts and codified according to the anatomical therapeutic chemical classification. On this basis we excluded drugs also prescribed before hospital admission. Drugs considered for the analysis were the following: ACE-inhibitors (ACEI), angiotensin calcium channel blockers (CCBs), antiplatelet drugs (APL), vitamin $\mathrm{K}$ antagonists (VKAs) drugs and heparin.

\section{Outcome measures}

The primary outcomes of this study were: 1) in-hospital mortality; 2) cognitive impairment at discharge; 3) functional status at discharge.

Cognitive and functional status was assessed at the time of admission and at discharge. Cognitive function was assessed using the Hodkinson Abbreviated Mental Test (HAMT), a 10-item screening test for dementia [7]. The following questions are put to the patient. Each question correctly answered scores one point. A score of 6 or less suggests delirium or dementia, although further and more formal tests are necessary to confirm the diagnosis.

The presence of cognitive impairment was identified by the presence of $\geq 4$ errors on the test administered at discharge.

Functional status was evaluated using 6 basic activities of daily living (ADL) [8]. Activities of Daily Living (ADLs) is a term used in healthcare to refer to daily self-care activities within an individual's place of residence, in outdoor environments, or both. Health professionals routinely refer to the ability or inability to perform ADLs as a measurement of the functional status of a person, particularly in regards 
to people with disabilities and the elderly. ADLs are defined as "the things we normally do" such as feeding ourselves, bathing, dressing, grooming, work, homemaking, and leisure. They include transferring from bed to chair, walking in a small room, eating, bathing, using the toilet, and personal hygiene procedures. Patients were considered "severe disability" if they needed intensive assistance in at least one activity of daily living and were considered "mild-moderate disability" if they needed only supervision or limited assistance in at least one activity of daily living at the time of discharge from the hospital.

\section{Statistical analysis}

We intended to assess the association between outcome indicators of acute ischemic stroke (no in-hospital mortality, in-hospital mortality, HAMT >6, HAMT $<6$; no $A D L$-impaired or 1-2 $A D L$ ) with some potential predictive variables such as demographic data (age, male sex), laboratory variables (glucose blood levels, cholesterol plasma levels, white body cell count), clinical variables [systolic blood pressure (SBP) at admission, diastolic blood pressure (DBP) at admission, Charlson index score at admission] and in-hospital treatment with cardiovascular drugs such as statins, ACE-inhibitors, ARBs, antiplatelet drugs, antivitamin-k drugs and heparin.

This was primarily done by tabulating the outcome categories against each chosen potential predictive variable (yes vs. no). The proportions of patients with or without in-hospital mortality, with and without cognitive impairment and with and without 1-6 impaired ADL were compared using contingency tables and the $\chi^{2}$ test. Therefore, we performed a forward logistic regression analysis respectively with indexes of favorable outcome at discharge such as no in-hospital mortality, HAMT $>6$ and $0 \mathrm{ADL}$ impaired as the dependent variable (separately for each outcome indicator). Variables for this analysis were selected from univariate analysis (Student $t$ test, contingency tables, and Mann-Whitney $U$ test) when they reached a significance of $\leq 0.05$. For all the statistical analyses, the results were considered significant when $P<0.05$. All statistical analyses were performed with the SPSS software.

\section{Results}

Demographic, clinical and laboratory variables in recruited patients are shown in Table 1. We enrolled 1096 subjects with acute ischemic stroke; 516 were male and 580 female, $391(41.4 \%)$ had a history of hypertension and 198 (20.98\%) a history of diabetes.

Data for HAMT score at discharge was only available for $514(46.89 \%)$ patients.

Data for $\mathrm{n}^{\circ}$ of $\mathrm{ADL}$ impaired at discharge was only available for 843 (76.91\%).

With regard to outcome indicators during hospital stay, there were $247(22.53 \%)$ in-hospital death, 237 (46.10\% of the 514 available) subjects showed a HAMT $<6$ at discharge, whereas 550 (65.24\% of the 843 available) had 1-6 ADL impaired at discharge.
Table 1 Selected general and clinical characteristics in patients with acute cerebrovascolar syndrome.

\begin{tabular}{|c|c|}
\hline \multicolumn{2}{|l|}{ Pts with acute ischemic stroke } \\
\hline Number & 1096 \\
\hline Age (years) & $73.452 \pm 6.2$ \\
\hline Female: $(n)(\%)$ & $580(52.91)$ \\
\hline Male: $(n)(\%)$ & $515(46.98)$ \\
\hline Hypertension (n) (\%) & $391(41.4)$ \\
\hline Diabetes (\%) (n) & $198(20.9)$ \\
\hline $\mathrm{T}^{\circ}$ at admission $\left({ }^{\circ} \mathrm{C}\right)$ & $36.9 \pm 0.72$ \\
\hline Length of hospital stay (days) & $15.4 \pm 6.4$ \\
\hline Glucose blood levels (mg/dl) & $132.89 \pm 65.17$ \\
\hline $\mathrm{SBP}(\mathrm{mm} / \mathrm{Hg})$ & $159.9 \pm 28.73$ \\
\hline $\mathrm{SBP}>140(\%)(n)$ & $420(38.3)$ \\
\hline $\mathrm{DBP}(\mathrm{mm} / \mathrm{Hg})$ & $87.16 \pm 13.2$ \\
\hline $\mathrm{DBP}>90 \mathrm{~mm} / \mathrm{Hg}$ & $177 / 16.16$ \\
\hline WBC at admission (per $\mathrm{mm}^{3}$ ) & $8996 \pm 3887$ \\
\hline Neutrophils (\%) at admission & $74.0 \pm 15.38$ \\
\hline $\operatorname{ESR}(\mathrm{mm} / \mathrm{h})$ & $28.4 \pm 15.0$ \\
\hline Total cholesterol plasma level (mg/dl) & $213.6 \pm 4.0$ \\
\hline Trigliceryde plasma level (mg/dl) & $155.2 \pm 76.1$ \\
\hline Charlson index (mean/median) & $2.95 / 3$ \\
\hline \multicolumn{2}{|l|}{ Charlson index score } \\
\hline - <2 (n) (\%) & $333(30.38)$ \\
\hline - $>2(n)(\%)$ & $763(69.61)$ \\
\hline In-hospital death (n) (\%) & $247(22.53)$ \\
\hline HAMT at discharge (total number*) (n) (\%) & $514(46.89)$ \\
\hline HAMT $<6$ (at discharge) $(n)(\%)$ & $237(46.10)$ \\
\hline HAMT >6 (at discharge) (n) (\%) & $277(53.89)$ \\
\hline ADL (total number**) (n) (\%) & $843(76.91)$ \\
\hline - No ADL impaired & $293(34.75)$ \\
\hline - 1-6 ADL impaired & $550(65.24)$ \\
\hline \multicolumn{2}{|l|}{ Treatment during hospital stay } \\
\hline - Statin & - \\
\hline - Ace-inhibitors $(n)(\%)$ & $180(16.42)$ \\
\hline - $\mathrm{CCB}$ & 469 (42.79) \\
\hline - AT-1 antagonists $(n)(\%)$ & - \\
\hline - Antiplatelet drugs $(n)(\%)$ & $220(20.07)$ \\
\hline - Anti-vitamin-k drugs (n) (\%) & $43(3.9)$ \\
\hline - Heparin e (n) (\%) & $398(36.31)$ \\
\hline
\end{tabular}

Regarding the type of cardiovascular treatment during hospital stay, no patients were treated with statins, 180 (16.42\%) were treated with ACE-inhibitors, no patients with ARBs, $220(20.07 \%)$ were treated with antiplatelets, 469 (42.79\%) with CCBs, 43 (3.9\%) with AVK drugs and 398 (36.31\%) with heparin.

At univariate analysis (see Table 2) patients with no inhospital mortality compared to those with intra-hospital mortality were more likely to have: lower age, lower blood glucose level at admission, a lower percentage of subjects with blood glucose levels $>200 \mathrm{mg} / \mathrm{dl}$, a higher SBP at admission, a higher percentage of patients with SBP $\geq 120 \mathrm{~mm} / \mathrm{Hg}$ and $\leq 180 \mathrm{~mm} / \mathrm{Hg}$, a higher percentage of subjects with DBP $>90 \mathrm{~mm} / \mathrm{Hg}$, higher plasma levels of total cholesterol, a lower white body cell count a lower Charlson index score, a higher percentage of subjects with Charlson index score $<2$, a higher percentage of subjects with 0 ADL impaired, a higher percentage of subjects who 
Table 2 Variables related to outcome (intra-hospital mortality, disability and cognitive function) at discharge in patients with acute ischemic stroke at univariate analysis.

\begin{tabular}{|c|c|c|c|c|c|c|c|c|c|}
\hline & $\begin{array}{l}\text { Intrahospital } \\
\text { death }\end{array}$ & $\begin{array}{l}\text { No intra-hospital } \\
\text { death }\end{array}$ & $P$ & HAMT $>6$ & $\mathrm{HAMT}<6$ & $P$ & No ADL-impaired & 1-2 ADL-impaired & $P$ \\
\hline $\mathrm{n} / \%$ & $247(22.53)$ & $849(77.46)$ & & $277(53.89)$ & $237(46.10)$ & & $293(34.75)$ & $550(65.24)$ & \\
\hline Age & $80.49 \pm 7.35$ & $75.65 \pm 6.46$ & $<0.005$ & $79.23 \pm 8.66$ & $81.33 \pm 7.23$ & 0.041 & $72.85 \pm 0.38$ & $78.49 \pm 9.25$ & $<0.005$ \\
\hline Sex (\% men) & $113(45.74)$ & 391 (46.05\%) & 0.37 & $163(58.84)$ & 99 (41.77) & $<0.001$ & $164(55.97)$ & $297(54)$ & 0.038 \\
\hline Blood glucose at admission & $158.29 \pm 83.38$ & $126.14 \pm 57.62$ & $<0.01$ & $124.05 \pm 61.81$ & $143.16 \pm 84.4$ & $<0.001$ & $123.74 \pm 60.18$ & $137.28 \pm 73.31$ & 0.021 \\
\hline $\begin{array}{l}\text { Glucose blood levels } \\
>200 \mathrm{mg} / \mathrm{dl}(\mathrm{n} / \%)\end{array}$ & $35(14.17)$ & $63(7.42)$ & $<0.005$ & $38(13.71)$ & $24(10.12)$ & $<0.001$ & $34(11.60)$ & $111(20.18)$ & $<0.005$ \\
\hline SBP at admission $(\mathrm{mm} / \mathrm{Hg})$ & $148.80 \pm 32.69$ & $160.16 \pm 27.87$ & $<0.0001$ & $151.18 \pm 26.08$ & $153.04 \pm 27.52$ & 0.06 & $154.28 \pm 27.23$ & $149.32 \pm 28.13$ & 0.045 \\
\hline DBP at admission $(\mathrm{mm} / \mathrm{Hg})$ & $86.63 \pm 15$ & $87.26 \pm 12.96$ & 0.78 & $84.84 \pm 14.04$ & $85.85 \pm 12.67$ & 0.07 & $84.18 \pm 13.53$ & $85.89 \pm 13.27$ & 0.78 \\
\hline $\mathrm{SBP} \geq 120$ and $\leq 180 \mathrm{~mm} / \mathrm{Hg}$ & $72(29.14)$ & $458(53.94)$ & $<0.0001$ & $86(31.03)$ & $55(23.20)$ & 0.021 & $91(31.05)$ & $123(22.36)$ & $<0.005$ \\
\hline $\mathrm{SBP}<120 \mathrm{~mm} / \mathrm{Hg}$ & 77 (31.17) & $191(22.49)$ & 0.022 & $100(36.10)$ & 99 (41.77) & 0.041 & $104(35.49)$ & $228(41.45)$ & 0.031 \\
\hline $\mathrm{SBP}>180 \mathrm{mmHg}$ & $98(39.67)$ & $200(29.51)$ & 0.033 & $91(32.85)$ & $83(35.83)$ & 0.65 & $98(33.44)$ & $199(36.18)$ & 0.75 \\
\hline $\mathrm{DBP}>90 \mathrm{~mm} / \mathrm{Hg}(\mathrm{n} / \%)$ & $68(27.93)$ & 146 (17.19) & 0.021 & $55(19.85)$ & 49 (20.67) & 0.41 & $61(20.81)$ & $104(18.90)$ & 0.21 \\
\hline $\begin{array}{l}\text { Cholesterol plasma } \\
\text { levels }(\mathrm{mg} / \mathrm{dl})\end{array}$ & $191.74 \pm 51.75$ & $200.53 \pm 50.92$ & 0.039 & $202.32 \pm 20.92$ & $194.54 \pm 31.75$ & 0.038 & $199.74 \pm 51.75$ & $201.53 \pm 50.92$ & 0.43 \\
\hline $\begin{array}{l}\text { Triglyceride plasma } \\
\text { levels }(\mathrm{mg} / \mathrm{dl})\end{array}$ & $148.48 \pm 91.01$ & $145.74 \pm 87.36$ & 0.37 & $156.8 \pm 57.01$ & $145.74 \pm 87.36$ & 0.023 & $147.83 \pm 91.01$ & $144.54 \pm 67.36$ & 0.07 \\
\hline Diabetes mellitus (n/\%) & $39(15.78)$ & 147 (17.31) & 0.38 & $53(19.13)$ & $44(18.56)$ & 0.61 & $55(18.77)$ & $102(18.54)$ & 0.45 \\
\hline White body cell (WBC) & $11001.27 \pm 4408.8$ & $8467 \pm 3557.8$ & $<0.0001$ & $6297 \pm 4251$ & $9495 \pm 3029$ & 0.011 & $8990 \pm 2251$ & $9.840 \pm 3251$ & 0.04 \\
\hline$W B C>10,000$ & $41(16.59)$ & $90(10.61)$ & $<0.05$ & $74(26.71)$ & $74(31.22)$ & 0.021 & $44(15.01)$ & $143[25]$ & $<0.005$ \\
\hline Charlson index (mean) & 3.9 & 3.1 & 0.035 & 3.76 & 3.83 & 0.87 & $3.9 / 4$ & $4 / 4.2$ & $<0.005$ \\
\hline Charlson index $<2(\mathrm{n} / \%)$ & $166(67.21)$ & $728(85.75)$ & $<0.05$ & $192(69.31)$ & $121(51.05)$ & 0.021 & $181(61.77)$ & $343(62.36)$ & 0.71 \\
\hline Charlson index $>2(\mathrm{n} / \%)$ & $81(32.79)$ & $121(14.25)$ & $<0.0001$ & $86(31.04)$ & $47(19.83)$ & $<0.005$ & $107(36.51)$ & $206(37.45)$ & 0.56 \\
\hline AMTD $>6(n / \%)$ & $69(28.39)$ & $236 / 31.42 \%$ & 0.55 & - & - & & $172(58.70)$ & $323(58.72)$ & 0.70 \\
\hline AMTD $<6(n / \%)$ & $46(23.95)$ & $231(30.75)$ & 0.021 & - & - & & $175(59.72)$ & $226(41.09)$ & 0.56 \\
\hline $\begin{array}{l}0 \text { ADL impaired } \\
(\mathrm{n} / \%)\end{array}$ & $76(30.71)$ & $414(55.1)$ & $<0.0001$ & $91(32.85)$ & $48(20.25)$ & $<0.005$ & - & - & - \\
\hline $\begin{array}{l}\text { 1-6 ADL impaired ( } \mathrm{n} / \%) \\
\text { Intra-hospital drugs }\end{array}$ & $36(18.75)$ & 337 (44.87) & $<0.0001$ & $186(67.14)$ & $193(81.43)$ & $<0.005$ & - & - & - \\
\hline Statin (n/\%) & - & - & & - & - & & & & \\
\hline Ace-inhibitors (n/\%) & $46(18.62)$ & $224(26.38)$ & 0.021 & $64(23.10)$ & $39(16.45)$ & 0.010 & $76(27.43)$ & $43(18.14)$ & $<0.005$ \\
\hline AT1-antagonists (n/\%) & - & - & - & - & - & - & - & - & - \\
\hline Calcium-channel blockers (n/\%) & 77 (31.17) & $398(46.87)$ & $<0.0001$ & $75(27)$ & $46(19.40)$ & 0.011 & $54(19.49)$ & $55(23.20)$ & 0.06 \\
\hline Antiplatelet drugs ( $\mathrm{n} / \%)$ & $24(9.71)$ & $267(31.44)$ & $<0.0001$ & $45(16.24)$ & $35(14.76)$ & 0.41 & 37 (13.35) & $35(14.76)$ & 0.11 \\
\hline Vitamin $\mathrm{K}$ antagonists (VKAs) (n/\%) & $21(8.59)$ & $77(9.06)$ & 0.41 & $9(3.24)$ & $8(3.37)$ & 0.22 & $12(4.33)$ & 7 (2.95) & 0.067 \\
\hline Heparine $(\mathrm{n} / \%)$ & $99(40.08)$ & $198(23.22)$ & $<0.005$ & $17(6.13)$ & $10(4.21)$ & 0.77 & $11(3.97)$ & $14(5.90)$ & 0.41 \\
\hline
\end{tabular}


Table 3 Logistic regression with no-intrahospital mortality.

\begin{tabular}{|c|c|c|c|c|}
\hline & Regression coefficient & Odds ratio & $95 \% \mathrm{Cl}$ & $P$ \\
\hline Age & -0.11 & 0.91 & $0.92-0.99$ & 0.024 \\
\hline SBP at admission (n/\%) & 1.61 & 5.55 & $1.42-17.8$ & 0.012 \\
\hline $\mathrm{SBP} \geq 120$ and $\leq 180 \mathrm{~mm} / \mathrm{Hg}$ & 1.48 & 2.78 & $1.97-3.35$ & $\leq 0.0001$ \\
\hline $\mathrm{SBP}<120 \mathrm{~mm} / \mathrm{Hg}$ & -0.22 & 0.75 & $0.5-0.98$ & 0.012 \\
\hline $\mathrm{SBP}>180 \mathrm{mmHg}$ & -0.33 & 0.73 & $0.66-0.81$ & $\leq 0.0001$ \\
\hline White body cell (WBC) & -0.21 & 0.78 & $0.5-0.89$ & 0.010 \\
\hline Cholesterol plasma levels & 1.38 & 2.12 & $1.33-4.3$ & 0.012 \\
\hline Glucose blood levels $>200$ mg/dl & -0.32 & 0.75 & $0.65-0.80$ & $\leq 0.0001$ \\
\hline Charlson index $<2$ (n/\%) & 1.02 & 4.12 & $1.42-17.8$ & 0.012 \\
\hline Charlson index >2 (n/\%) & -0.27 & 0.80 & $0.65-0.91$ & 0.022 \\
\hline Ace-inhibitors & 1.92 & 3.88 & $1.89-8.2$ & $<0.05$ \\
\hline Calcium antagonists & 1.71 & 5.56 & $1.77-9.4$ & 0.010 \\
\hline Antiplatelet drugs & 1.65 & 4.23 & $2.7-8.3$ & 0.014 \\
\hline Heparin & -0.22 & 0.79 & $0.43-0.89$ & $\leq 0.0001$ \\
\hline
\end{tabular}

Dependent variable: no intra-hospital mortality.

had in-hospital treatment with ACE-inhibitors, calciumantagonist and antiplatelet drugs and a lower percentage of patients treated during hospital stay with heparine.

At univariate analysis (see Table 2) patients with HAMT $<6$ at discharge compared to those with HAMT $>6$ at discharge showed: a lower age, lower blood glucose level at admission, a lower percentage of subjects with blood glucose levels $>200 \mathrm{mg} / \mathrm{dl}$, a higher percentage of subjects with SBP $\geq 120 \mathrm{~mm} / \mathrm{Hg}$ and $\leq 180 \mathrm{~mm} / \mathrm{Hg}$, higher levels of plasma total cholesterol, higher levels of plasma triglyceride, a lower white body cell count, a higher percentage of subjects with Charlson index score $<2$, a higher percentage of subjects with $0 \mathrm{ADL}$ impaired, a higher percentage of subjects that had in-hospital treatment with ACE-inhibitors, a higher percentage of subjects that had inhospital treatment with CCBs.
At univariate analysis (see Table 2 ) patients with 0 ADL impaired at discharge compared to those with $>2 \mathrm{ADL}$ at discharge were more likely to have: a lower age, lower blood glucose level, a lower percentage of subjects with blood glucose levels $>200 \mathrm{mg} / \mathrm{dl}$, a higher SBP at admission, a higher percentage of subjects with SBP $\geq 120 \mathrm{~mm} / \mathrm{Hg}$ and $\leq 180 \mathrm{~mm} / \mathrm{Hg}$, a higher percentage of subjects with DBP $>90 \mathrm{~mm} / \mathrm{Hg}$, a lower white body cell count, a lower Charlson index score, a higher percentage of subjects with Charlson index score $<2$, a higher percentage of subjects with $0 \mathrm{ADL}$ impaired, a higher percentage of subjects that had a in-hospital treatment with ACE-inhibitors.

At logistic regression analysis no in-hospital mortality was significantly associated with SBP values at admission, with a SBP $\geq 120$ and $\leq 180 \mathrm{~mm} / \mathrm{Hg}$ at admission, cholesterol plasma levels, Charlson index $<2$ and with in-hospital

Table 4 Logistic regression with HAMT $>6$

\begin{tabular}{|c|c|c|c|c|}
\hline & Regression coefficient & Odds ratio & $95 \% \mathrm{Cl}$ & $P$ \\
\hline Age & -0.16 & 0.88 & $0.70-0.91$ & 0.035 \\
\hline Glucose blood levels $>200$ mg/dl & -0.29 & 0.85 & $0.46-0.79$ & $<0.05$ \\
\hline $\mathrm{SBP} \geq 120$ and $\leq 180 \mathrm{~mm} / \mathrm{Hg}$ & 1.52 & 2.41 & $1.48-4.7$ & 0.012 \\
\hline $\mathrm{SBP}<120 \mathrm{~mm} / \mathrm{Hg}$ & -0.17 & 0.87 & $0.67-0.94$ & 0.025 \\
\hline $\mathrm{SBP}>180 \mathrm{~mm} / \mathrm{Hg}$ & -0.29 & 0.85 & $0.46-0.79$ & $<0.05$ \\
\hline Cholesterol plasma levels (mg/dl) & -0.35 & 0.70 & $0.45-0.88$ & 0.025 \\
\hline Diabetes mellitus & -0.30 & 0.79 & $0.56-0.93$ & 0.021 \\
\hline White body cell (WBC) & -0.27 & 0.77 & $0.67-0.96$ & 0.017 \\
\hline Charlson index $<2$ & 1.47 & 3.45 & $1.79-4.96$ & 0.010 \\
\hline Charlson index $>2$ & -0.29 & 0.88 & $0.59-0.96$ & 0.032 \\
\hline $0 \mathrm{ADL}$ impaired & 1.41 & 3.70 & $2.21-7.9$ & $<0.05$ \\
\hline 1-6 ADL impaired & -0.27 & 0.81 & $0.63-0.80$ & 0.019 \\
\hline Ace-inhibitors & 1.81 & 3.99 & $2.11-8.3$ & $<0.0001$ \\
\hline Antiplatelet drugs & 1.77 & 3.85 & $2.21-8.77$ & $<0.05$ \\
\hline Heparin & -0.69 & 0.70 & $0.29-0.88$ & 0.020 \\
\hline
\end{tabular}

Dependent variable: MMSE $>6$ at discharge. 
Table 5 Logistic regression with no ADL impaired.

\begin{tabular}{lllll}
\hline & Regression coefficient & Odds ratio & $95 \% \mathrm{Cl}$ & $P$ \\
\hline Age & -0.11 & 0.87 & $0.70-0.95$ & 0.030 \\
Glucose blood levels $>200 \mathrm{mg} / \mathrm{dl}$ & -0.31 & 0.82 & $0.29-0.81$ & $<0.05$ \\
$\mathrm{SBP} \geq 120$ and $\leq 180 \mathrm{~mm} / \mathrm{Hg}$ & 1.51 & 2.07 & $1.64-2.66$ & $\leq 0.0001$ \\
$\mathrm{SBP}<120 \mathrm{~mm} / \mathrm{Hg}$ & 0.33 & 0.85 & $0.39-0.81$ & $<0.05$ \\
$\mathrm{SBP}>180 \mathrm{mmHg}$ & 0.88 & 0.98 & $0.44-1.01$ & 0.021 \\
White body cell $(\mathrm{WBC})$ & -0.30 & 0.71 & $0.56-0.82$ & 0.020 \\
WBC $>10,000$ & -0.29 & 0.69 & $0.50-0.83$ & 0.019 \\
Charlson index $>2$ & -0.30 & 0.80 & $0.57-0.80$ & $<0.05$ \\
Charlson index $<2$ & 1.37 & 2.44 & $1.70-8.5$ & $\leq 0.0001$ \\
Ace-inhibitors & 1.81 & 2.17 & $1.55-7.05$ & $<0.05$ \\
Calcium-antagonist & 1.60 & 2.88 & $1.44-8.11$ & $\leq 0.0001$ \\
Antiplatelet drugs & 1.59 & 2.77 & $1.88-8.21$ & $\leq 0.0001$ \\
Heparin & -0.27 & 0.80 & $0.59-0.96$ & 0.012 \\
\hline
\end{tabular}

Dependent variable: no ADL impairment at discharge.

treatment with $\mathrm{ACE}$-inhibitors, $\mathrm{CCbs}$ and antiplatelet drugs (see Table 3).

At logistic regression analysis HAMT $<6$ at discharge was significantly associated with SBP at admission, SBP $\geq 120$ and $\leq 180 \mathrm{~mm} / \mathrm{Hg}$ at admission, Cholesterol plasma levels, Charlson index $<2$ and with in-hospital treatment with ACEinhibitors and antiplatelet drugs (see Table 4).

At logistic regression no $A D L$ impaired at discharge was significantly associated with SBP $\geq 120$ and $\leq 180 \mathrm{~mm} / \mathrm{Hg}$ $(\mathrm{n} / \%)$, Charlson index $<2$ and with intra-hospital treatment with ACE-inhibitors and antiplatelet drugs (see Table 5).

\section{Discussion}

Our study suggests that if a patient with acute ischemic stroke has, at admission, an SBP $\geq 120$ and $\leq 180 \mathrm{~mm} / \mathrm{Hg}$, higher total cholesterol plasma levels, a lower Charlson index, the short term outcome in terms of in-hospital mortality and functional indicators such as cognitive and functional status at discharge is better.

Admission blood pressure (BP) and significant decreases in BP after acute stroke have been correlated with outcome. Few data are available on the impact of extreme values at any time point within the first $24 \mathrm{~h}$ but a recent study showed that diurnal BP variations influence the course of BP after acute stroke [9].

Extreme hypertension and hypotension on admission have both been correlated with adverse outcome in acute stroke patients [9-15]. However, there is no consensus of the "optimal range" of BP [16]. Elevations in systolic or diastolic blood pressure (BP) are observed in up to $80 \%$ of patients after an acute ischemic stroke, even in previous normotensives.

Our findings show a higher percentage of patients with SBP $\geq 120$ and $\leq 180 \mathrm{~mm} / \mathrm{Hg}$ in subjects with no in-hospital mortality, no cognitive impairment and no dependency at discharge and that at logistic regression all the outcome indicators that we evaluated (in-hospital mortality, cognitive impairment at discharge, functional status at discharge) were significantly associated with SBP values at admission and in particular with a SBP $\geq 120$ and $\leq 180 \mathrm{~mm} /$ $\mathrm{Hg}$ at admission. The relationship between higher SBP values and a better outcome are not a novel finding, but no study, to our knowledge, evaluated cognitive impairment evaluated through HAMT score and functional status through ADL evaluation as outcome indicators in patients with acute ischemic stroke in relation to systolic blood pressure at admission.

Moreover, these findings could provide a possible confirmation of the latest recommendations of clinical guidelines from American Heart Association/American Stroke Association Stroke Council [17] indicating that rapid and steep reductions in blood pressure might be harmful and that antihypertensive treatment should be withheld unless the diastolic blood pressure is $\geq 120 \mathrm{~mm} \mathrm{Hg}$ or unless the systolic blood pressure is $\geq 220 \mathrm{~mm}$.

Our findings concerning higher median levels of plasma total cholesterol in subjects with better outcome after an acute ischemic stroke and the reported association at logistic regression between cholesterol plasma levels and no-intrahospital mortality are consistent with these previous reports.

Several studies evaluated the prognostic importance of various stroke characteristics and social, demographic, and medical factors in patients with the most severe strokes but few studies examined the role of medical treatment $[18,19]$, but these studies have focused exclusively on tissue plasminogen activator (tPA). Although few studies examined the impact of pre-treatment with other medical treatment such as ACE-inhibitors, statins, and antiplatelet drugs [20-22], no study to our knowledge has addressed the role of in-hospital treatment with cardiovascular drugs such as antihypertensive, antiplatelet and hypocholesterolemic drugs used in the acute phase of stroke during the in-hospital stay on stroke outcome.

We report that patients with no in-hospital mortality had a higher percentage of patients that have in-hospital treatment with ACE-inhibitors, calcium-antagonist and antiplatelet drugs.

Our study also shows at univariate analysis and at logistic regression analyses that patients receiving ACE-inhibitors, 
calcium channel blockers and antiplatelet drugs during hospital stay after an acute ischemic stroke were more likely to have no in-hospital mortality. In-hospital treatment with ACE-inhibitors and with antiplatelet in our patients was associated with all the good outcome indicators (no in-hospital mortality, HAMT $>6$ and 0 ADL impaired). These are interesting and, to our knowledge, novel findings. The role of antihypertensive drugs in the acute phase of ischemic stroke represents a controversial issue. In a recent study the administration of antihypertensives was more strongly associated with poor outcome than any BP threshold violation [22]. Nevertheless one study indicated that pre-stroke use of ACE-inhibitors may result in additive reduction in stroke severity, as measured by NIH Stroke Scale, and the volume of ischemic tissue at risk, as assessed by perfusion-weighted imaging-diffusionweighted imaging mismatch [22].

We also reported a higher percentage of patients receiving treatment with calcium channel blockers in subjects with better outcome. Despite the advancing knowledge of calcium signalling in neurite outgrowth and recovery, little is known about the clinical effect of calcium antagonism during the recovery period following stroke. Recently Dowlatshahi et al. [21] showed in a cohort from the registry of the Canadian Stroke Network that in subjects with ischemic stroke there was no change in 6-month mortality in terms of treatment with ACEI, B-blockers or diuretics at discharge and that subjects that were admitted on CCBs had improved outcome at 6-months if they were also discharged on CCB, compared to patients who had their CCBs discontinued.

Our findings also show a lower percentage of patients treated with heparins in subjects with better outcome, underlining a possible association between heparine and poor outcome indicators.

The exact role of heparins in hyper-acute stage of ischemic stroke is still unclear. Nevertheless our findings may suggest a disadvantage, perhaps linked to an extension of the ischemic lesion or a higher rate of hemorrhagic transformation although we currently do not have bibliographic data in support of this finding.

Some possible limitations of our study are that we used two uncommonly used scores for functional measures of stroke outcome: HAMT score and ADL impairment score. We choose these scores because the GIFA Database did not evaluate scores of acute neurological deficit such as National Institute of Health Stroke Scale (NIHSS) or Scandinavian Stroke Scale Score (SSS), nor Rankin score or Barthel index as a disability score. Furthermore, given the short time frame at evaluation (discharge), the HAMT score may not accurately reflect long-term cognitive impact of stroke, after accounting for stroke recovery in the chronic stage. The ADL score, likewise, at discharge may not accurately reflect stroke recovery. So a delayed follow-up is necessary to assess long-term outcomes. Nevertheless, HAMT is effective as a screening tool for cognitive impairment with older, community dwelling, hospitalized and institutionalized adults even in acute cerebrovascular patients [23], whereas ADL evaluation [24] has been used to determine the influence of initially lowered orientation on rehabilitation outcome in stroke patients.
Other possible limitations of our study are the retrospective analysis, the availability of HAMT score only in 614 patients of the 1096 with acute ischemic stroke, and the almost complete absence of patients treated with statin because we analyzed data obtained from 1993 to 1998, which wasn't a period of wide-spread statin treatment. Nevertheless this limitation represents, in our opinion, a possible advantage since our study evaluated the relationship of some cardiovascular active drugs such as ACEinhibitors, calcium-channel-blockers, antiplatelet drugs in subjects not treated with statins, and hence shows the real effects of these drugs on stroke prognosis independently of statin treatment that in the last years showed their positive effect on stroke outcome $[25,26]$.

Finally another limitation is the possibility of a "reversecausality" bias is most likely, since only those patients who were not severely-ill (e.g. were not comatose, dysphagic) might have been given some cardiovascular pills during hospital-stay.

Some conclusions can be drawn from our data nevertheless.

First, we found that some clinical and laboratory variables such as systolic blood pressure, cholesterol blood levels, and glucose blood levels are associated with prognosis in terms of in-hospital mortality, cognitive function and functional outcome.

Second, we report that the use of ACE-inhibitors, calcium channel blockers and antiplatelet drugs administered in the acute phase of ischemic stroke may improve the outcome of patients, whereas heparin use is associated with a worse short term outcome. Definitive recommendations for the use of these drugs in stroke patients must await further experimental and clinical data although our study suggests that for maximum benefit, this type of therapy should be initiated within the first few hours of an ischemic stroke with careful monitoring of blood pressure.

\section{References}

[1] Yoon SS, Dambrosia J, Chalela J, Ezzeddine M, Warach S, Haymore J, et al. Rising statin use and effect on ischemic stroke outcome. BMC Med 2004 Mar 23;2:4.

[2] Sanossian N, Saver JL, Rajajee V, Selco SL, Kim D, Razinia T, et al. Premorbid antiplatelet use and ischemic stroke outcomes. Neurology 2006;66(3):319-23.

[3] Kumar S, Savitz S, Schlaug G, Caplan L, Selim M. Antiplatelets, ACE inhibitors, and statins combination reduces stroke severity and tissue at risk. Neurology 2006;66:1153-8.

[4] Tuttolomondo A, Di Sciacca R, Di Raimondo D, Pedone C, La Placa S, Pinto A, et al. Effects of clinical and laboratory variables and of pretreatment with cardiovascular drugs in acute ischaemic stroke: a retrospective chart review from the GIFA study. Int J Cardiol; 2010 July 1.

[5] Carosella L, Pahor M, Pedone C, Zuccala G, Manto A, Carbonin P. Pharmacosurveillance in hospitalized patients in Italy. Study design of the 'Gruppo Italiano di Farmacovigilanza nell'Anziano' (GIFA). Pharmacol Res 1999;40:287-95.

[6] Deyo RA, Cherkin DC, Ciol MA. Adapting a clinical comorbidity index for use with ICD-9-CM administrative databases. J Clin Epidemiol 1992 Jun;45(6):613-9.

[7] Hodkinson HM. Evaluation of a mental test score for assessment of mental impairment in the elderly. Age Ageing 1972;1: 233-8. 
[8] Jongbloed L. Prediction of function after stroke: a critical review. Stroke 1986;17:765-76.

[9] Ritter MA, Kimmeyer P, Heuschmann PU, Dziewas R, Dittrich R, Nabavi DG, et al. Blood pressure threshold violations in the first 24 hours after admission for acute stroke: frequency, timing, predictors, and impact on clinical out come. Stroke 2009 Feb;40(2):462-8.

[10] Stead LG, Gilmore RM, Decker WW, Weaver AL, Brown Jr RD. Initial emergency department blood pressure as predictor of survival after acute ischemic stroke. Neurology 2005;65: 1179-83.

[11] Yong M, Diener HC, Kaste M, Mau J. Characteristics of blood pressure profiles as predictors of long-term outcome after acute ischemic stroke. Stroke 2005;36:2619-25.

[12] Jorgensen HS, Nakayama H, Raaschou HO, Olsen TS. Effect of blood pressure and diabetes on stroke in progression. Lancet $1994 ; 344$.

[13] Leonardi-Bee J, Bath PM, Phillips SJ, Sandercock PA. IST Collaborative group. Blood pressure and clinical outcomes in the international stroke trial. Stroke 2002;33:1315-20.

[14] Vemmos KN, Tsivgoulis G, Spengos K, Synetos A, Manios E, Vassilopoulou $S$, et al. Blood pressure course in acute ischaemic stroke in relation to stroke subtype. Blood Press Monit 2004;9:107-14.

[15] Ahmed N, Nasman P, Wahlgren NG. Effect of intravenous nimodipine on blood pressure and outcome after acute stroke. Stroke 2000;31:1250-5.

[16] Vemmos KN, Tsivgoulis G, Spengos K, Zakopoulos N, Synetos A, Manios E, et al. U-shaped relationship between mortality and admission blood pressure in patients with acute stroke. J Intern Med 2004;255:257-65.

[17] Adams Jr HP, del Zoppo G, Alberts MJ, Bhatt DL, Brass L, Furlan A, et al. American heart association; American Stroke Association Stroke Council; Clinical Cardiology Council; cardiovascular Radiology and Intervention Council; Atherosclerotic peripheral vascular disease and Quality of care outcomes in Research Interdisciplinary working groups. Guidelines for the early management of adults with ischemic stroke: a guideline from the American heart Association/American stroke association stroke Council, clinical Cardiology Council, cardiovascular Radiology and Intervention Council, and the Atherosclerotic peripheral vascular disease and Quality of care outcomes in Research Interdisciplinary working groups: the American Academy of Neurology affirms the value of this guideline as an educational tool for neurologists. Stroke 2007 May;38(5):1655-711.

[18] Jørgensen HS, Nakayama H, Raaschou HO, Olsen TS. Acute stroke: prognosis and a prediction of the effect of medical treatment on outcome and health care utilization. The Copenhagen Stroke Study. Neurology 1997 Nov;49(5): 1335-42.

[19] Jorgensen HS, Kammersgaard LP, Houth J, Nakayama $H$, Raaschou HO, Larsen K, et al. Who benefits from treatment and rehabilitation in a stroke unit? A Community-based Study Stroke 2000 Feb;31(2):434-9.

[20] Selim M, Savitz S, Linfante I, Caplan L, Schlaug G. Effect of pre-stroke use of ACE inhibitors on ischemic stroke severity. BMC Neurol 2005;5:10. doi:10.1186/1471-2377-5-10.

[21] Dowlatshahi D, Fang J, Kawaja M, Hakim A. Use of calcium channel blockers after stroke is not associated with poor outcome: a cohort from the registry of the Canadian stroke network. J Neurol 2006 Nov;253(11):1478-83.

[22] Di Napoli M, Papa F. Angiotensin-converting enzyme inhibitor use is associated with reduced plasma concentration of Creactive protein in patients with first-ever ischemic stroke. Stroke 2003;34(12):2922-9.

[23] Lincoln NB, Parry RH, Vass CD. Randomized, controlled trial to evaluate increased intensity of physiotherapy treatment of arm function after stroke. Stroke 1999;30:573-9.

[24] Pedersen PM, Jorgensen HS, Nakayama H, Raashou UHO, Olsen TS. Orientation in the acute and chronic stroke patient: impact on ADL and social activities. The Copenhagen Stroke Study. Arch physical medicine Rehabilitation 1996;77(4): 336-9.

[25] Martí-Fàbregas J, Gomis M, Arboix A, Aleu A, Pagonabarraga J, Belvís R, et al. Favorable outcome of ischemic stroke in patients pretreated with statins. Stroke 2004 May;35(5): 1117-21.

[26] Reeves MJ, Gargano JW, Luo Z, Mullard AJ, Jacobs BS, Majid A. Paul Coverdell National acute stroke registry Michigan Prototype Investigators effect of pretreatment with statins on ischemic stroke outcomes. Stroke 2008 Jun;39(6):1779-88. 